\title{
Hoteles y sanatorios: influencia de la tuberculosis en la arquitectura del turismo de masas
}

\author{
Hotels and sanatoria: the influence of tuberculosis \\ on mass tourism architecture
}

\author{
Eduardo Jiménez \\ Morales \\ Docente e investigador, \\ Departamento de Arte y \\ Arquitectura/Escuela de \\ Arquitectura/Universidad de \\ Málaga. \\ Campus Universitario El Ejido \\ 29013 - Málaga - Málaga - España \\ eduardo_jm@uma.es
}

\section{Ingrid Carolina Vargas} Diaz

Investigadora y Arquitecta Autónoma.

Calle Hotel Pontinental 14-16, 2० B 29620 - Torremolinos - Málaga España

carovar@correo.ugr.es
JIMÉNEZ MORALES, Eduardo; VARGAS DÍAZ, Ingrid Carolina. Hoteles y sanatorios: influencia de la tuberculosis en la arquitectura del turismo de masas. História, Ciências, Saúde - Manguinhos, Rio de Janeiro, v.24, n.1, jan.mar. 2017, p.243-260.

\section{Resumen}

Este artículo pretende constatar la influencia que ha ejercido la tuberculosis en la formalización de la arquitectura del turismo de masas. Para ello se repasa la evolución tipológica del hotel a partir de la eclosión del sanatorio antituberculoso en el contexto de la estación turística alpina de mediados del siglo XIX. Un recorrido que se realiza tendiendo puentes entre los progresos en arquitectura y los avances en terapias médicas. El objetivo es hacer evidente el proceso de hibridación que se produce entre ambas tipologías arquitectónicas. Una imbricación que se extiende hasta la Segunda Guerra Mundial pero cuya influencia aún persiste en la arquitectura del turismo masivo de sol y playa.

Palabras clave: hotel; sanatorio; arquitectura; tuberculosis; turismo.

\section{Abstract}

The aim of this article is to verify the influence of tuberculosis on mass tourism architecture. To achieve this, the paper analyses the typological evolution of the hotel since the middle of the nineteenth century, when the first sanatoria appeared in the alpine resorts. A study that creates links between the progress in architecture and the medical therapy advances. The goal is to highlight the hybridisation process between both architectural typologies. Although this overlapping is developed until the Second World War, the influence of its mixture is still present in contemporary mass tourism architecture.

Keywords: hotel, sanatoria, architecture, tuberculosis, tourism. 
A lo largo de la historia, la evolución de las teorías médicas ha ejercido una destacada influencia sobre el progreso de la arquitectura. Principalmente porque a los cambios que se producen en los tratamientos de las enfermedades les suele acompañar una alteración del espacio arquitectónico que le permita implementarlos. Un progreso que es evidente entre las edificaciones hospitalarias pero cuyos resultados sirven a veces de referencia y llegan, incluso, a manifestarse en otros ámbitos de la disciplina. Tal como sucedió con el sanatorio, una institución especializada en el tratamiento de la tuberculosis y que en los años entre las dos guerras mundiales se convirtió en un modelo internacional para gran parte del diseño arquitectónico, incluso para la vivienda.

Precisamente la tuberculosis, y especialmente el sanatorio antituberculoso, han sido objeto de recientes estudios por parte de la teoría arquitectónica. Pero, si autores como Margaret Campbell (2005) y Paul Overy (2008) se centran en la influencia que ejerce el sanatorio en la arquitectura del movimiento moderno, este artículo va a abordar la aparición de los primeros sanatorios en el contexto de la estación turística alpina del siglo XIX y el papel que jugó la tuberculosis en la evolución de sus arquitecturas. En especial en la del hotel, que fue correceptor de la clientela tuberculosa al menos mientras se conseguía demostrar el carácter infeccioso de esta grave enfermedad.

De ahí que la preocupación de los médicos por la higiene y la funcionalidad, la orientación y la ventilación de las estancias o su vinculación con la naturaleza, se formalizara arquitectónicamente no solo en el sanatorio, sino también en el hotel. Una imbricación arquitectónica que se extendió hasta la Segunda Guerra Mundial, cuando la arquitectura terapéutica que promovía el sanatorio antituberculoso perdió protagonismo en el tratamiento de la enfermedad. Para entonces, la estreptomicina ya era mucho más efectiva en la lucha contra la tuberculosis que las curas climáticas de aire y de sol empleadas desde mediados del siglo XIX.

No obstante, basta con observar las características de la arquitectura turística que se desarrolló tras el conflicto bélico, para comprobar que la influencia del modelo sanatorial aún persiste. Sobre todo en el frente litoral, en los destinos adscritos al turismo de masas, de sol y de playa. Una semejanza que la teoría arquitectónica justifica argumentando que la arquitectura turística es, además de una variante del movimiento moderno, el resultado de la hibridación entre la vanguardia arquitectónica del siglo XX y las construcciones vernáculas de los destinos turísticos litorales.

Sin embargo, la arquitectura del turismo de masas puede ser el resultado del mismo proceso evolutivo que se inicia en la estación turística alpina del siglo XIX y que tiene como catalizador principal a la propia tuberculosis. Unos argumentos que pretenden ser demostrados a lo largo de este artículo.

Para comprobar esta hipótesis, se sigue un itinerario cronológico estructurado en tres apartados. Tanto el primero como el segundo, abordan las transformaciones arquitectónicas que experimentan el sanatorio y el hotel como resultado de la aplicación de las terapias médicas antituberculosas. Especialmente en las estaciones turísticas suizas, convertidas desde finales del siglo XIX en el gran sanatorio de Europa. El tercero, se centra en la formalización de la arquitectura para el turismo de masas como resultado de la traslación de estas transformaciones al frente litoral. Por último, se exponen las principales conclusiones. 


\section{La génesis del sanatorio en el contexto de la estación turística de montaña}

En el siglo XIX, en un mundo que se industrializa rápidamente, el viaje a la montaña representaba para la burguesía un reencuentro indispensable con lo natural como fuente de renovación física y espiritual. En gran parte, influenciado por las ideas románticas que propugnaron ese retorno a la naturaleza frente a los males que azotaban a la ciudad industrial. La tuberculosis era una de esas enfermedades, una gran desconocida que se propagó por toda Europa desde finales del siglo XVIII, y en torno a la que se construyó un contexto científico favorable al uso terapéutico del clima de montaña. Al menos hasta 1882, cuando Robert Koch identifica al bacilo causante de la enfermedad.

Caspar Friedrich Fuchs (1853) fue uno de los primeros en exaltar las propiedades salutíferas de las alturas para las dolencias pulmonares, haciendo un especial énfasis en las cualidades vivificantes del clima alpino. Unas hipótesis que se cimentaban en una supuesta inmunidad tísica de las poblaciones de montaña y que, a pesar de su débil base científica, fueron refrendadas por el doctor Hermann Brehmer en 1859. Fue entonces cuando la amplia difusión que otorgan las revistas científicas europeas a estas teorías médicas, desencadenó un interés inusitado por este fenómeno y, como consecuencia, una migración sin precedentes a la montaña desde el punto de vista sanitario.

Además, las terapias médicas se centraban, por lo general, en la práctica de ejercicio físico o en el reposo al aire libre y al sol. Unas actividades similares al estilo de vida que tenía lugar en las estaciones turísticas de montaña de la época. Una mezcla de prácticas deportivas en plena naturaleza y de vida austera, abanderada por amplios sectores de la élite social europea y a los que iba dirigida la insistente propaganda en torno a la bondad salutífera de estos lugares. Lo que terminó dibujando un contexto de hibridación entre prácticas turísticas y sanitarias a varios niveles, acentuado por la propagación de la tuberculosis, y que se hizo visible en la arquitectura.

En efecto, mientras se diseñan unas instalaciones acordes a las necesidades médicas, muchos de los hoteles de montaña pasan a acoger a una pudiente clientela de enfermos tuberculosos a pesar de no estar concebidos originalmente para este fin. Así se concluye tras el estudio de alguno de los primeros establecimientos de cura, como por ejemplo el sanatorio del doctor Hermann Brehmer en Göbersdorf (1859), que ocupaba las instalaciones de un Alte Kurhaus alemán (Figura 1). Un viejo hotel de montaña, cuyas instalaciones crecieron a partir de 1878 hasta alcanzar las trescientas habitaciones con un lujoso programa al servicio del ocio y del confort del paciente.

La propagación de este tipo de establecimientos se produce a gran velocidad gracias a la buena acogida que tiene la enfermedad entre los círculos sociales más exclusivos. Lo que diluyó los límites entre la arquitectura hospitalaria y la hotelera, piedra angular en la génesis de la institución que se especializa en el tratamiento de la enfermedad: el sanatorio. Además, sus similitudes se acrecientan ante la falta de consenso en torno al programa sanatorial, aprobado en el Congreso Internacional de la Tuberculosis de París en 1905 (Dumarest, Tobé, Lefevre, nov. 1936). Circunstancia que dificultó la fundación de unas instalaciones específicas, mientras que aceleró este proceso de hibridación. 


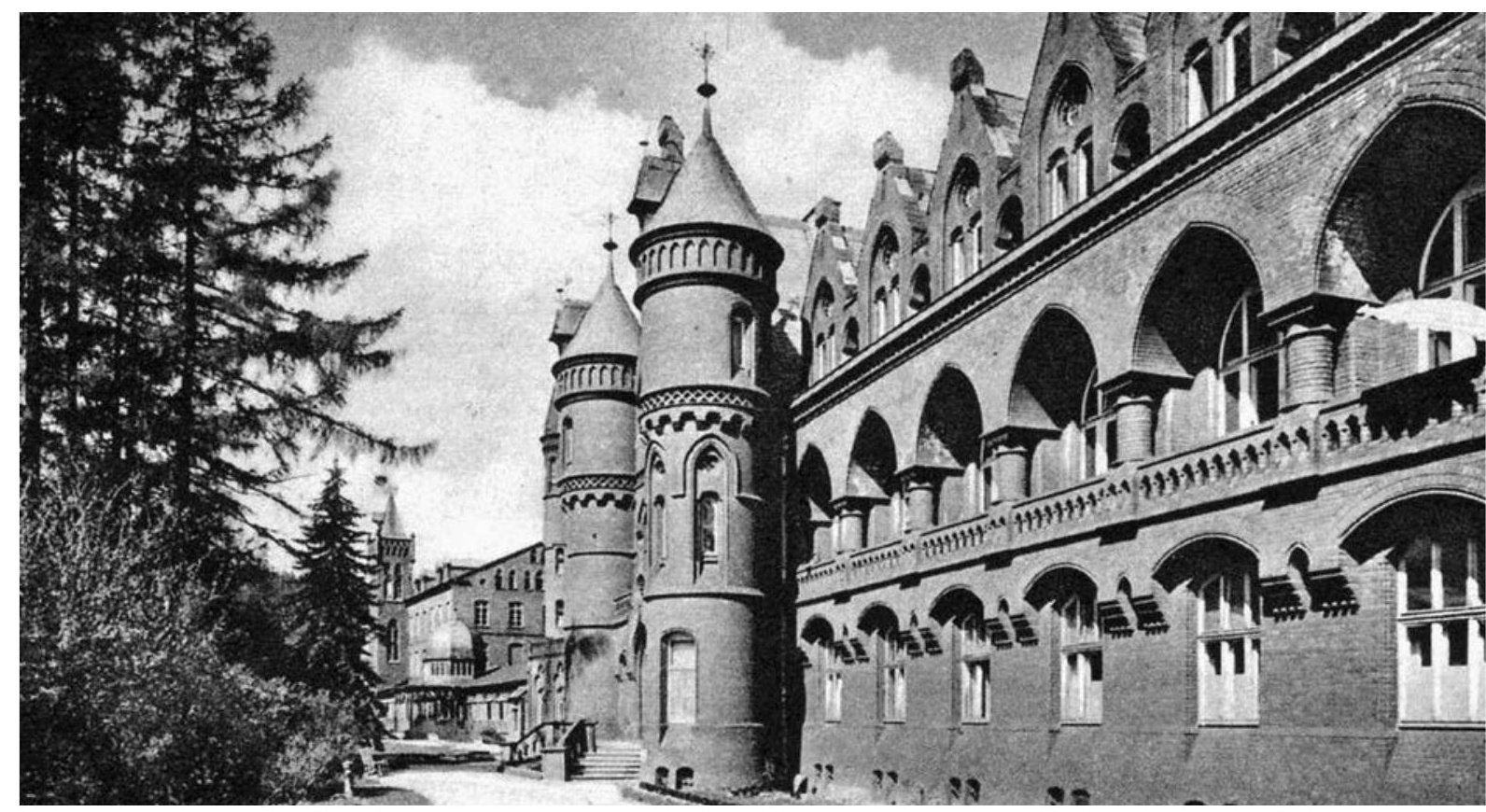

Figura 1: Sanatorio de Hermann Brehmer, 1859 (Knopf, 1904)

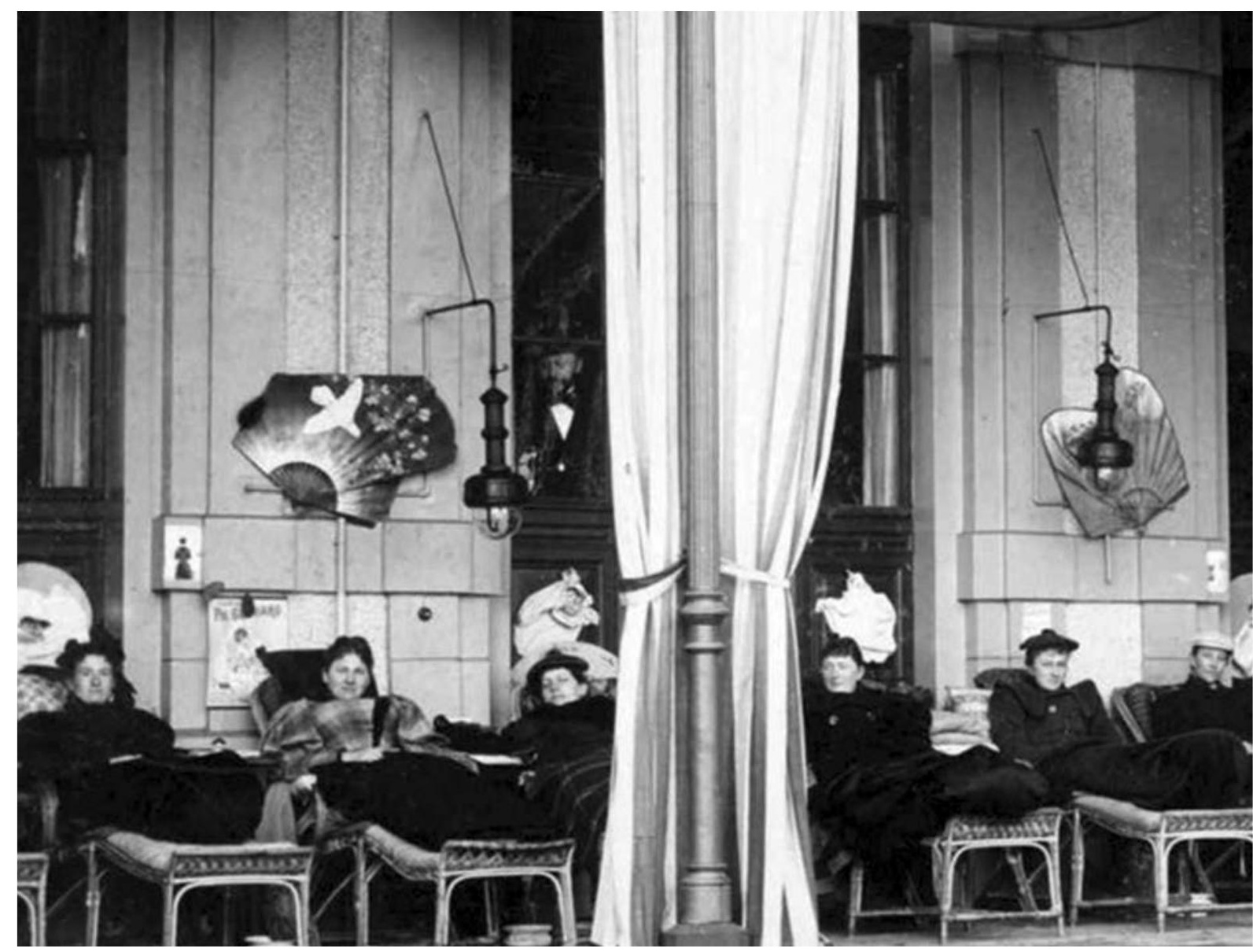

Figura 2: Liegehalle o galería de cura colectiva anexada a la planta baja del Falkenstein Sanatorium (Rüdiger, 1894) 
De ahí que la configuración arquitectónica del hotel experimente en pocas décadas una considerable evolución. De su formalismo neoclásico ${ }^{1}$ a una arquitectura funcional producto de las exigencias médicas. Sin duda, en el origen de esta transformación se encuentran las necesidades espaciales que reclama el doctor Peter Dettweiler para implementar su tratamiento de cura en 1876. Unos requerimientos que nacen al remplazar la práctica de ejercicio físico en las montañas por el reposo del paciente y, por tanto, con la necesidad de un espacio de mediación entre el interior y el exterior del edificio que asegure su contacto con las condiciones saludables del clima.

El resultado es una Liegehalle o galería de cura colectiva anexada a la planta baja del Falkenstein Sanatorium, que se materializa a través de un pórtico de hierro encastrado a la fachada meridional y sobre el que se disponen cubiertas textiles para regular la exposición del paciente al ambiente exterior (Figura 2). Del éxito de sus tratamientos se hacen eco las revistas médicas internacionales que convierten a este dispositivo efímero en una parte esencial en la concepción arquitectónica de cualquier sanatorio (Rufenacht, 1899). Así se recoge en las Actas del Congreso Internacional celebrado en Berlín, en 1902, donde se publican los primeros sanatorios de la época (Eager, 1902).

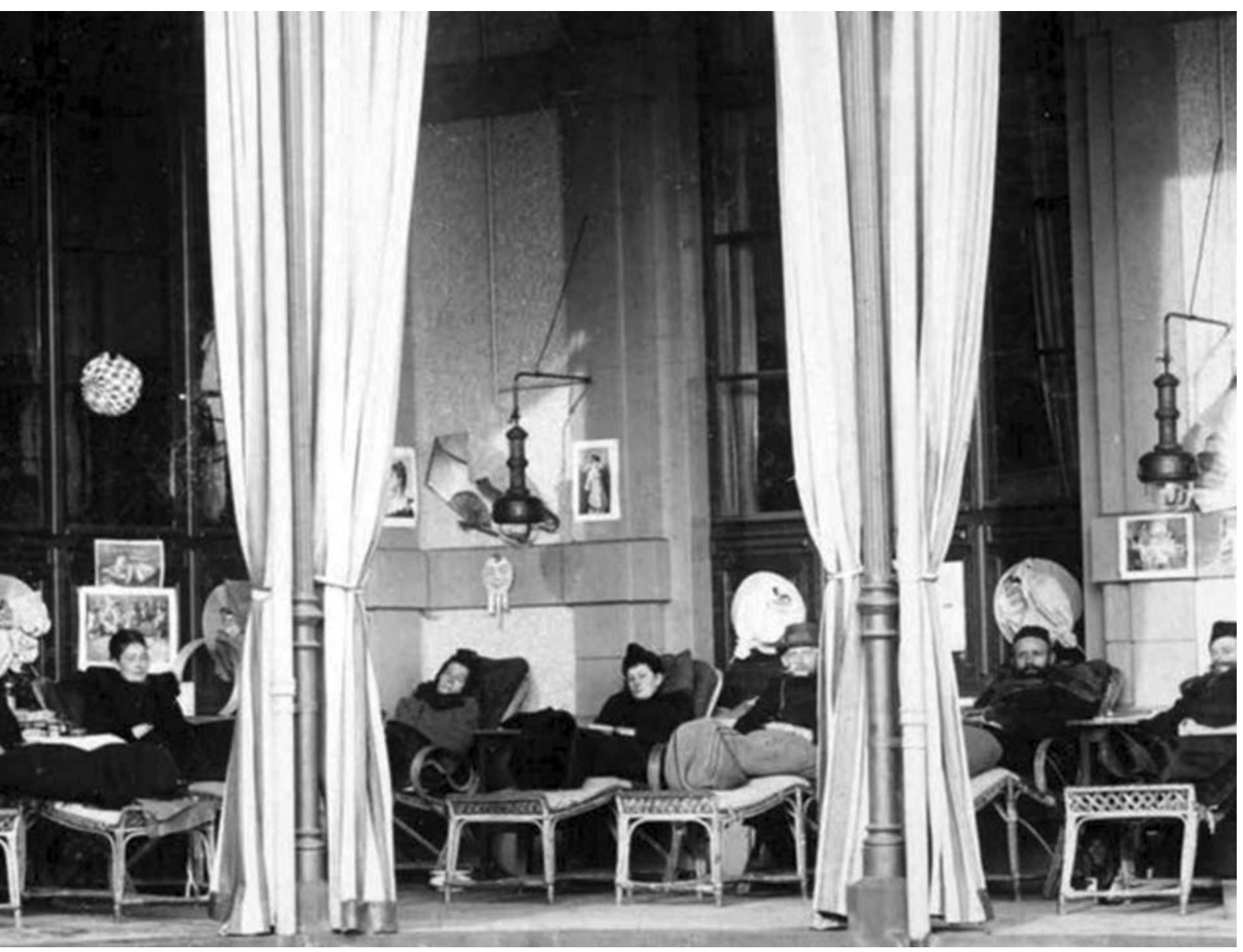




\section{Los Alpes suizos como laboratorio para la innovación arquitectónica}

Pero si existe un entorno geográfico donde se agudiza la hibridación arquitectónica entre hoteles y sanatorios, es el suizo. No solo por su potencial turístico sino porque a finales del siglo XIX también se convierte en el gran sanatorio de Europa. De hecho, sus hoteles no tardan en incorporar galerías de cura para satisfacer las necesidades de su extensa clientela tuberculosa. Es el caso del Grand Hotel Kronenhof-Bellavista en Pontresina o del Palace Hotel en Saint Moritz, al que se le incorpora, en 1896, una amplia Liegehalle con vistas al lago y a las montañas (Figura 3).

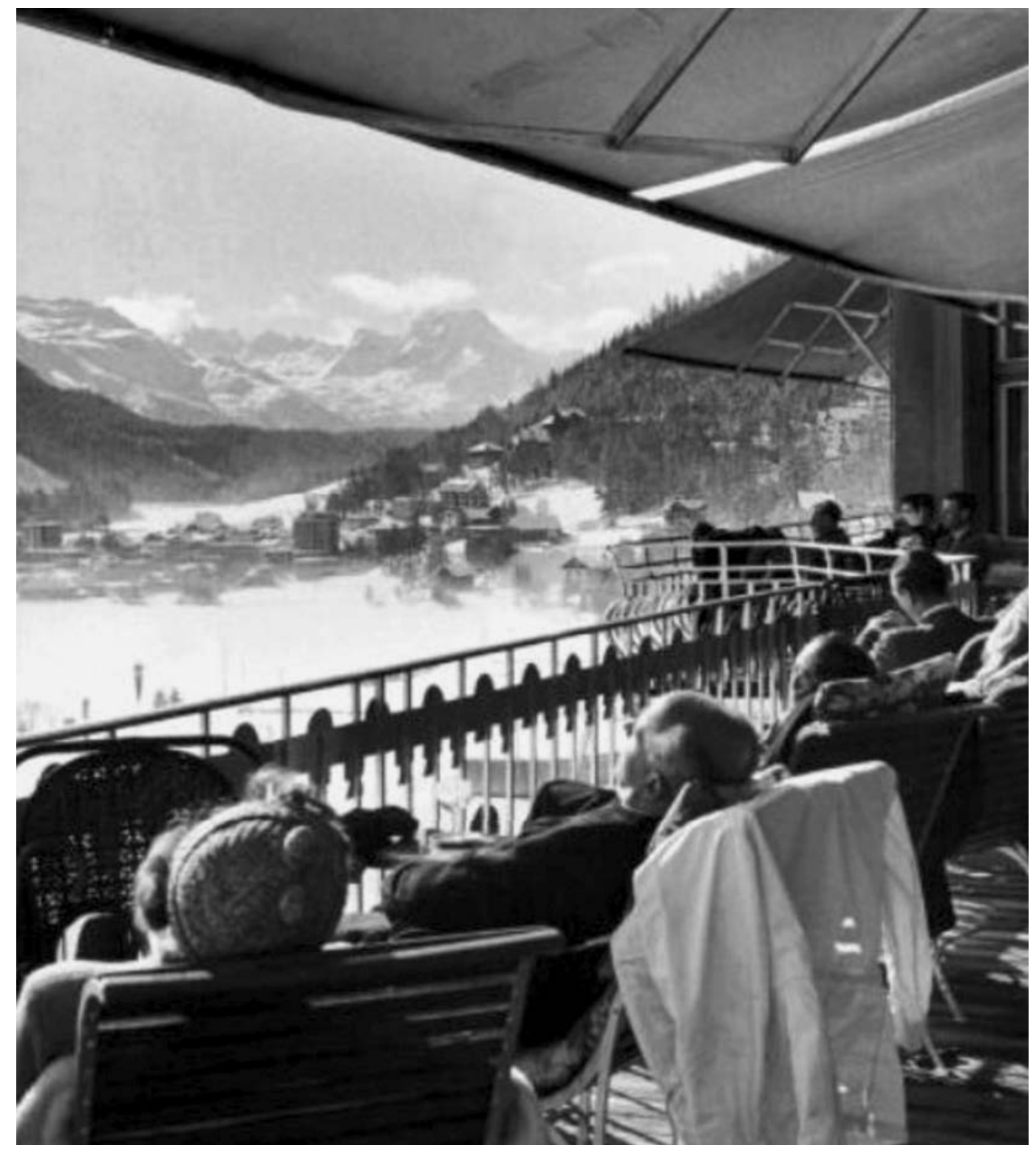

Figura 3: Terraza del Palace Hotel en St. Moritz (Gubler, 2008) 
Estas transformaciones fueron mucho más evidentes en algunas de las villas suizas que se destinan al tratamiento de la tuberculosis, motivo por el cual tuvieron que alterar sus criterios compositivos originales para adecuarse a las necesidades médicas de la época. Así le sucede a la Haus Caselva de Davos, al incorporar galerías de cura a través de una estructura de hierro fundido encastrada a su fachada romántica, ${ }^{2}$ a La Colline de Montreux, al renunciar al protagonismo compositivo de su hastial a favor de la fachada lateral orientada al sol del mediodía. Unas decisiones que responden a una necesidad indiscutible desde el punto de vista sanitario: el soleamiento.

Tanto es así que la fachada de La Colline carecía de una galería de cura colectiva en su planta baja. Para satisfacer las necesidades médicas, aparecen terrazas corridas en sus tres niveles, subdivididas por la estructura portante del edificio y que, a su vez, las vincula con las habitaciones (Figura 4). Conceptos que se llevan al límite a comienzos del siglo XX, cuando los arquitectos Max Haefeli y Otto Pflegard diseñan los sanatorios Schatzalp y Queen Alexandra en Davos. Sobre todo en este último, donde el ingeniero suizo Robert Maillart y el constructor francés François Hennebique implementan un sistema pionero de voladizos auto-portantes en hormigón armado (Figura 5).

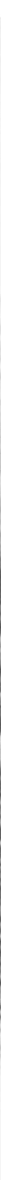

Figura 4: La Colline en Montreux, 1898 (Toulier, Cremnitzer, 2008) 


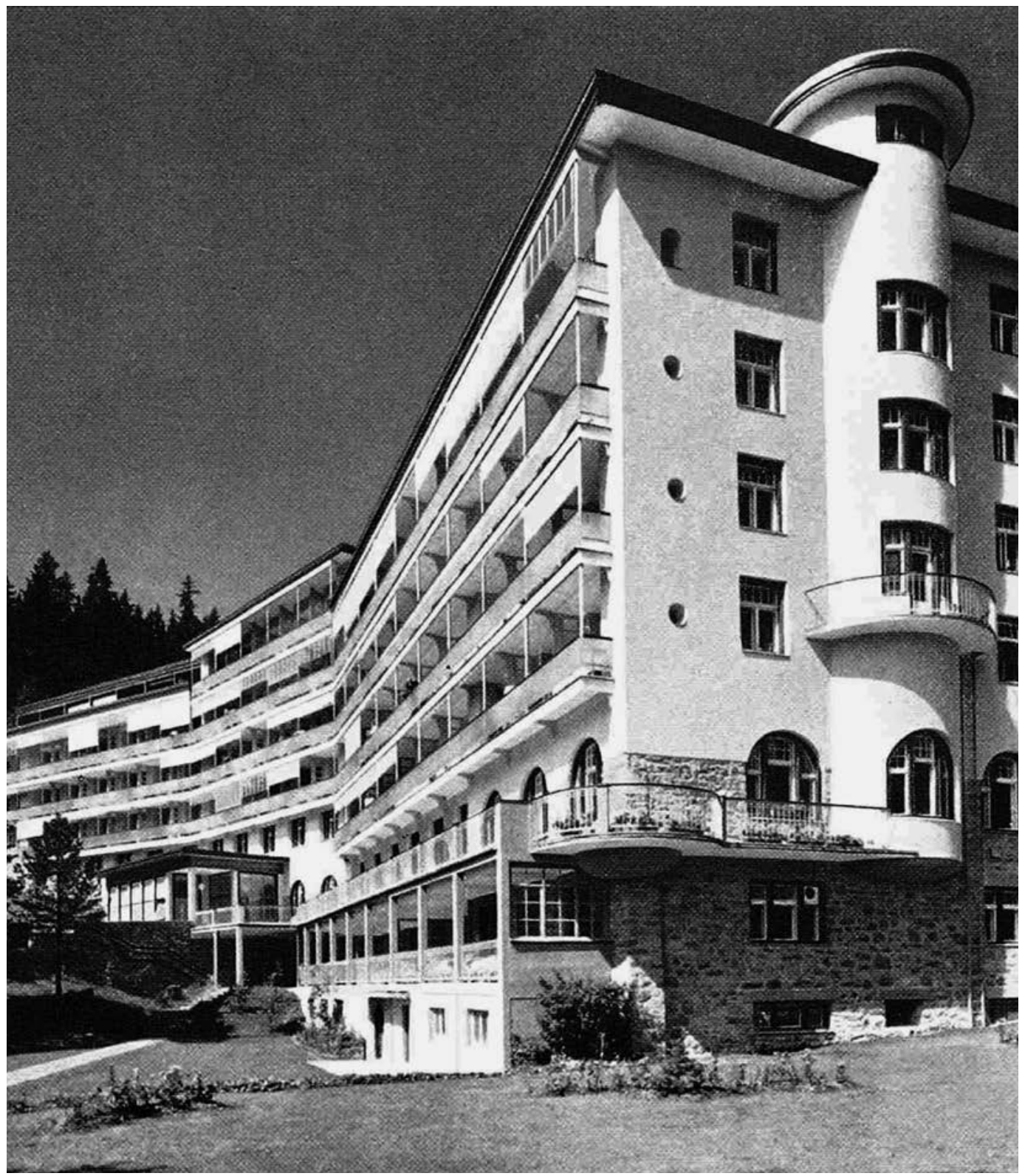

Figura 5: Sanatorio Queen Alexandra en Davos-Platz, 1906-1909 (Ausbau..., 1958)

Se da forma así a una fachada de terrazas corridas que solo se interrumpen por unas mamparas de vidrio que las individualizan. Además, por primera vez se consigue diluir el límite estructural que hasta ese momento evidenciaba el origen complementario de la galería de cura respecto al edifico principal. No hay que olvidar tampoco que el Queen Alexandra era un Volksheilstätte o sanatorio público, con recursos económicos limitados que fomentaron la racionalidad funcional y constructiva en su diseño. Por ello carece de decoración, sus formas se simplifican y el único elemento arquitectónico que es capaz de dar carácter al edificio son sus terrazas. 
Los hoteles no eran ajenos a estas innovaciones. De hecho, ellos compartían con los sanatorios no solo el uso de las terrazas, sino también la sectorización del programa y la simplificación del estilo arquitectónico. Además, los hoteles asimismo organizaban sus habitaciones de una manera similar, asegurándose de este modo el soleamiento y la buena ventilación de sus estancias. De ahí que los lucernarios o los patios interiores que caracterizaron a la hôtellerie suiza hasta 1870 fuesen rechazados por insalubres y que, en su lugar, se adoptase un esquema de distribución lineal similar al que desarrolló en 1887 el doctor Karl Turban para su primer sanatorio en Davos.

Este último disponía de una fila única de habitaciones orientadas al sur y accesibles desde un corredor septentrional. La misma que Eugéne Jost incorporaría al proyecto del Palace Hotel en Caux en 1906 (Figura 6). El resultado es un plan con alas articuladas en forma de "Y" que además de facilitar la concentración de usos, también maximizaba la exposición de sus habitaciones al aire y al sol a través de una extensa fachada abierta al mediodía. Un esquema similar al que desarrolla Jacques Gross para el Dolder Grand Hotel de Zúrich y que recuperaría después para su propuesta de un sanatorio ideal en el Concurso Internacional de Ideas en Inglaterra de 1902 (Figura 7).

Obviamente, estos intercambios arquitectónicos se aceleran gracias a que los mismos arquitectos abordan indistintamente ambos programas. Basta con observar el trabajo de Jacques Gross para el Wehrawald Sanatorium en 1901, así como el de Gaudenz Issler bajo la supervisión del doctor Karl Turban o el de los arquitectos Henri Vevey y Horace Edouard Davinet para el Grand Hotel Giessbach y el Victoria Sanatorium en Berna. De hecho, sendas versiones revisadas del Wehrawald Sanatorium se reproducen en las alas simétricas de la propuesta sanatorial ideal de Jacques Gross para Inglaterra.

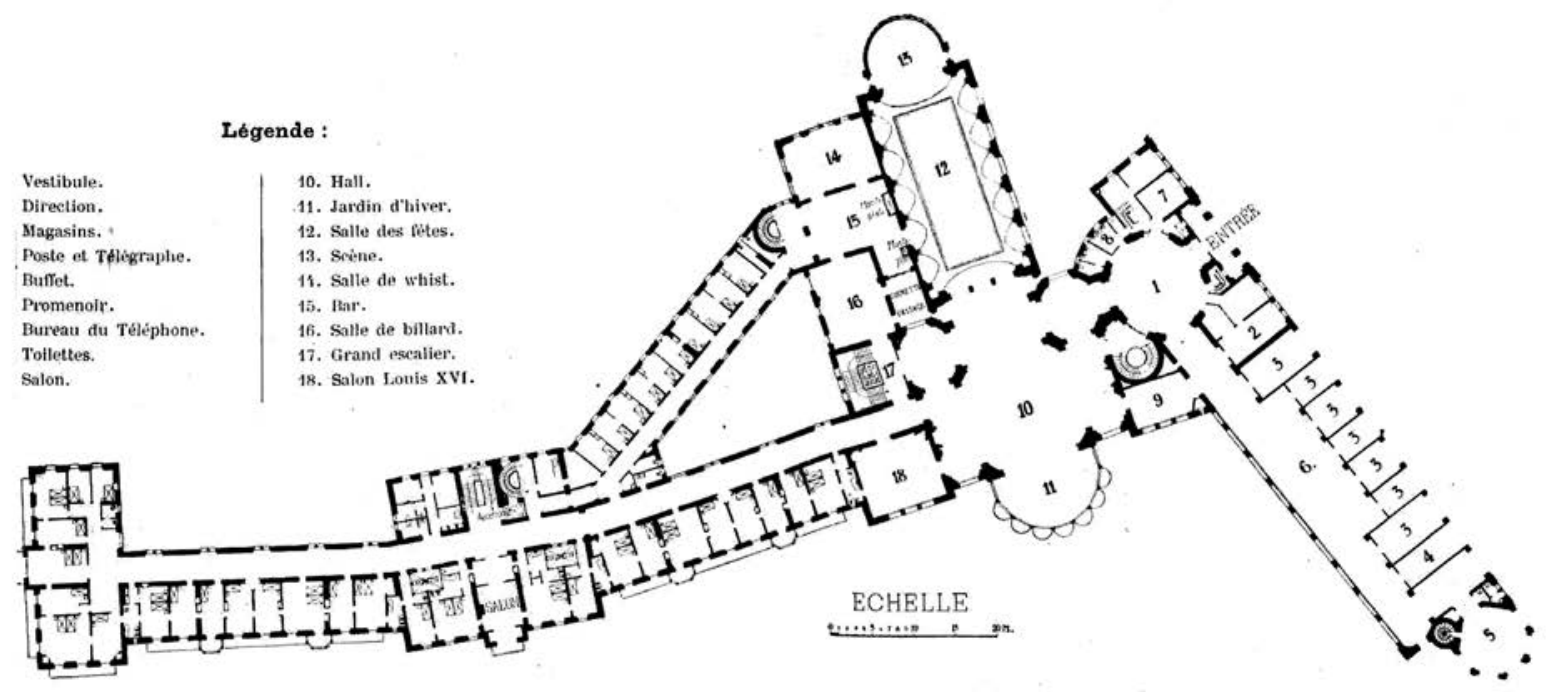

DE $X$ SUR TERRITET, VAUD

PLAN DU $4^{M E}$ ETAGE

M. JOST, A LAUSANNE

Figura 6: Plan del Palace Hotel en Caux, 1906 (Lüthi, 2001) 


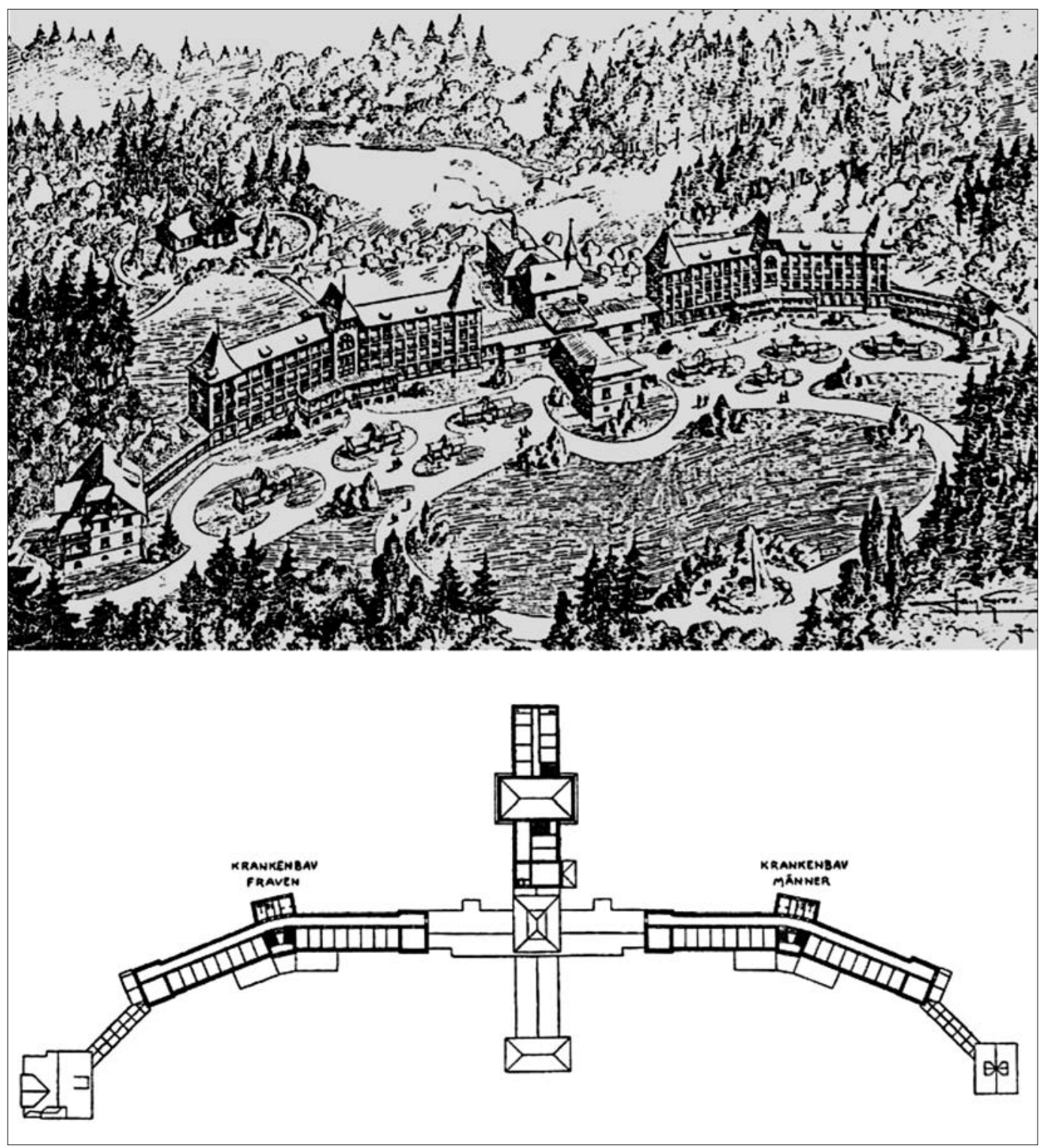

Figura 7: Propuesta de sanatorio ideal en Inglaterra, 1902 (Cremnitzer, 2005)

Las posibilidades que ofrece este último proyecto, sobre todo para implementar los distintos tratamientos antituberculosos, lo convierten en todo un referente para cualquier establecimiento de cura (Turban, 1909). También para el hotel, tal como se corrobora en los ejemplos anteriores. Se consolida de esta manera su ruptura con el esquema claustral y su consecuente transición hacia un modelo de hotel panorámico, abierto al aire y al sol (Figura 8). Una evolución inconcebible sin la innovadora arquitectura terapéutica que surge como respuesta a las necesidades del cuerpo médico y del interés por el asoleo o la ventilación cruzada de sus habitaciones. 


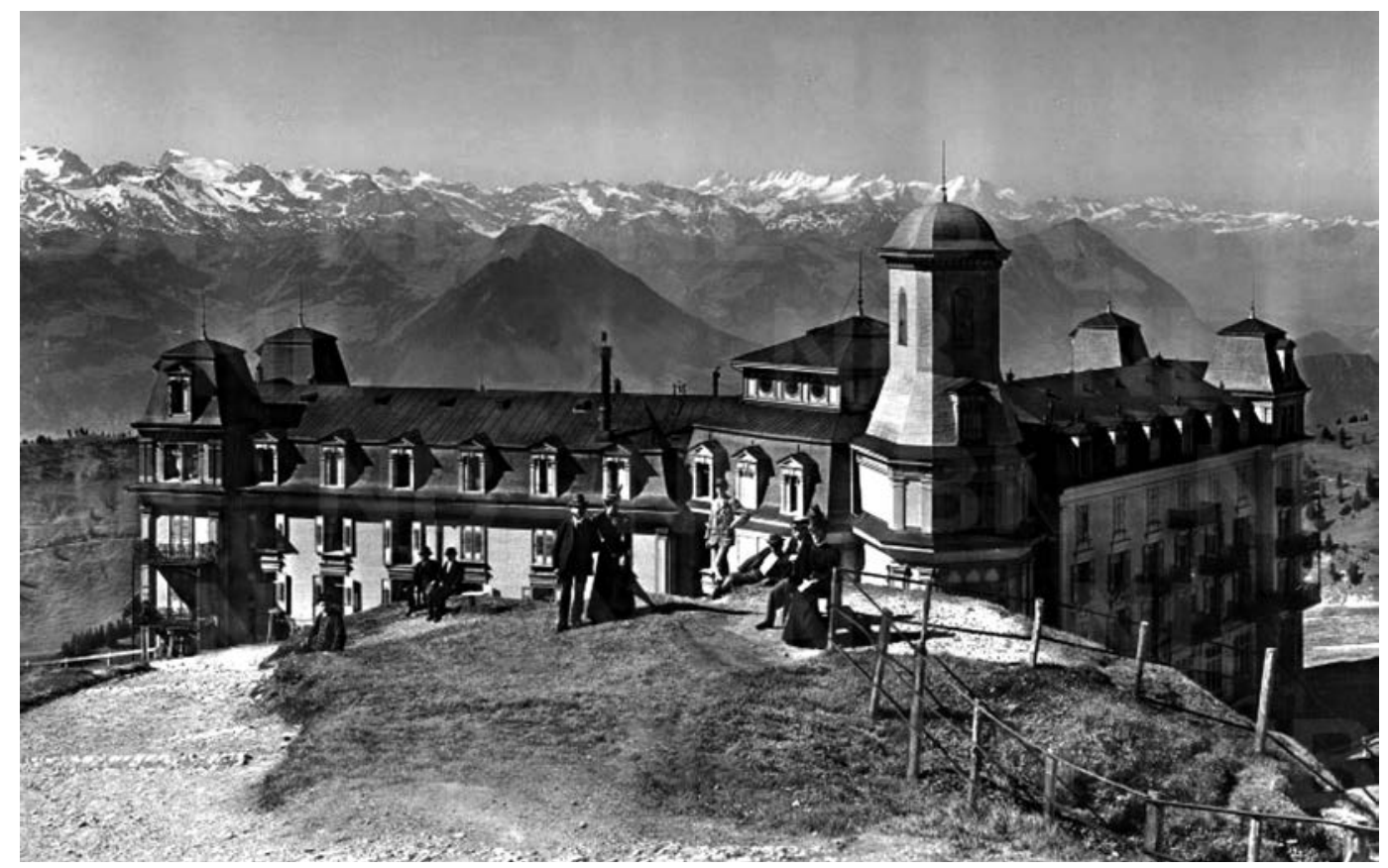

Figura 8: Grand Hotel Schreiber en el Righi-Kulm (Wehrli, 1897)

\section{La translación al frente del mar de la arquitectura terapéutica alpina}

Pero si a comienzos del siglo XX se consolida un modelo de hotel que no es muy diferente a un sanatorio, en el período entreguerras esta convergencia se hace aún más evidente. Con el estallido de la Primera Guerra Mundial, seguido de la crisis financiera de 1929, el número de clientes que acuden a la montaña con la intención de curarse disminuye drásticamente. Para compensarlos, las estaciones suizas se redirigen hacia el turismo deportivo, permitiendo así su reconversión al turismo activo. Por lo que gran parte del patrimonio sanatorial se destinó entonces a albergar hoteles, facilitando una vez más su intercambio arquitectónico.

Es el caso del sanatorio Bella Lui en Crans-Montana, convertido en hôtel de sport poco después de su inauguración en 1928. Un diseño de Rudolf y Flora Steiger-Crawford que proporciona continuidad al proceso de racionalización arquitectónica iniciado por el sanatorio Queen Alexandra en 1906 y que desde entonces se hace más visible en la arquitectura hotelera. Junto a él, y localizado en Mürren, el Hotel Alpina und Sporthotel Edelweiss de Arnold Itten también deja constancia de esta influencia (Figura 9). A ellos se les unen otros ejemplos que reproducen los mismos patrones arquitectónicos al finalizar la década de 1920, como el Hotel Monte Veritá en Ascona (Figura 10) o el Isla Mountain Hotel de Jakob Licht en Arosa.

Además, las políticas de salud pública y de bienestar social que promueven diversas organizaciones sociales municipales y sindicales centroeuropeas, desde 1924, permiten incorporar a una clientela adicional que hasta entonces no participaba de los circuitos habituales de la élite social europea: las clases media y trabajadora. En parte gracias a la necesidad que tenían los gobiernos de organizar el ocio y el tiempo libre al que tienen acceso estos sectores sociales a partir del primer tercio del siglo XX, así como por la pérdida del glamour que tuvo la tuberculosis entre las clases pudientes tras demostrarse el carácter infeccioso de esta grave enfermedad. 


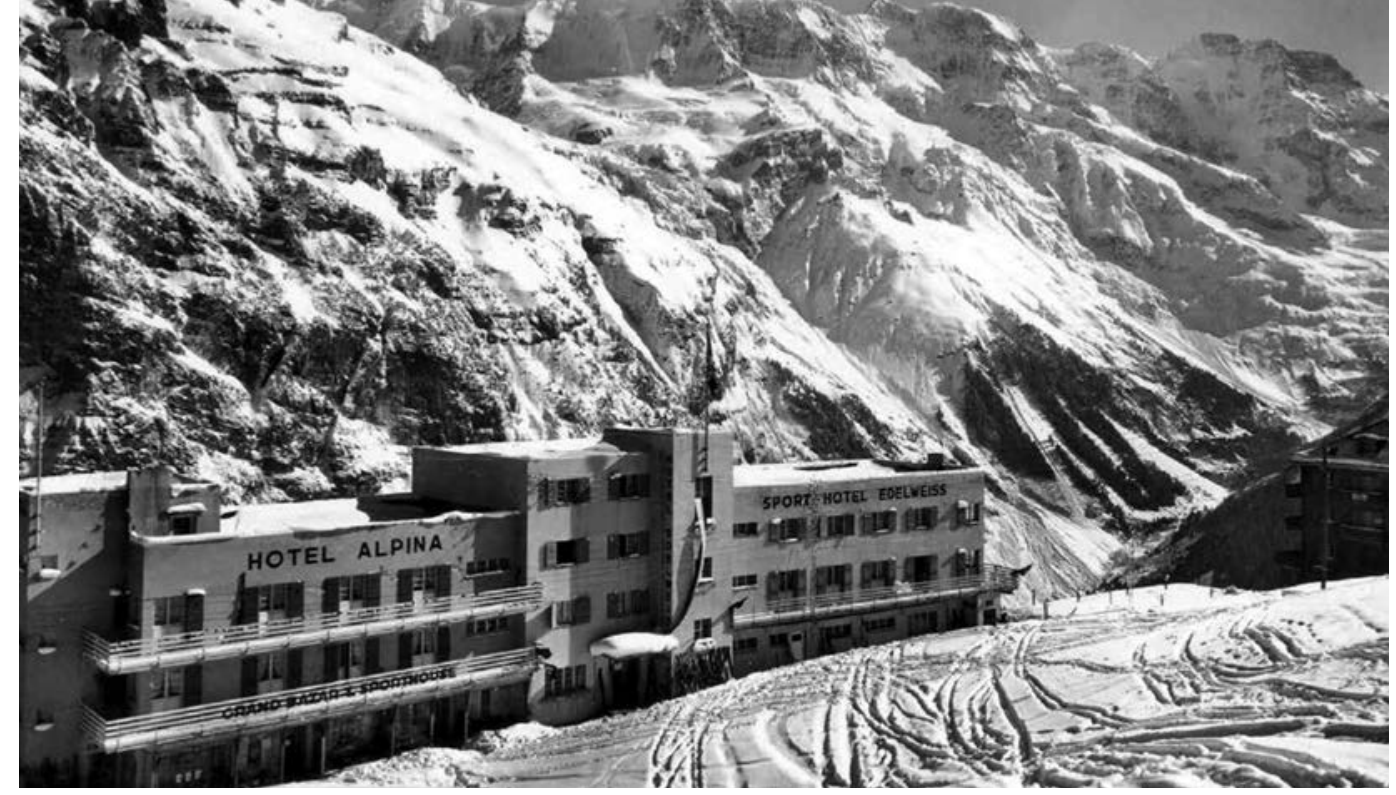

Figura 9: Hotel Alpina und Sporthotel Edelweiss en Mürren, 1928 (Gescheit, 1929)

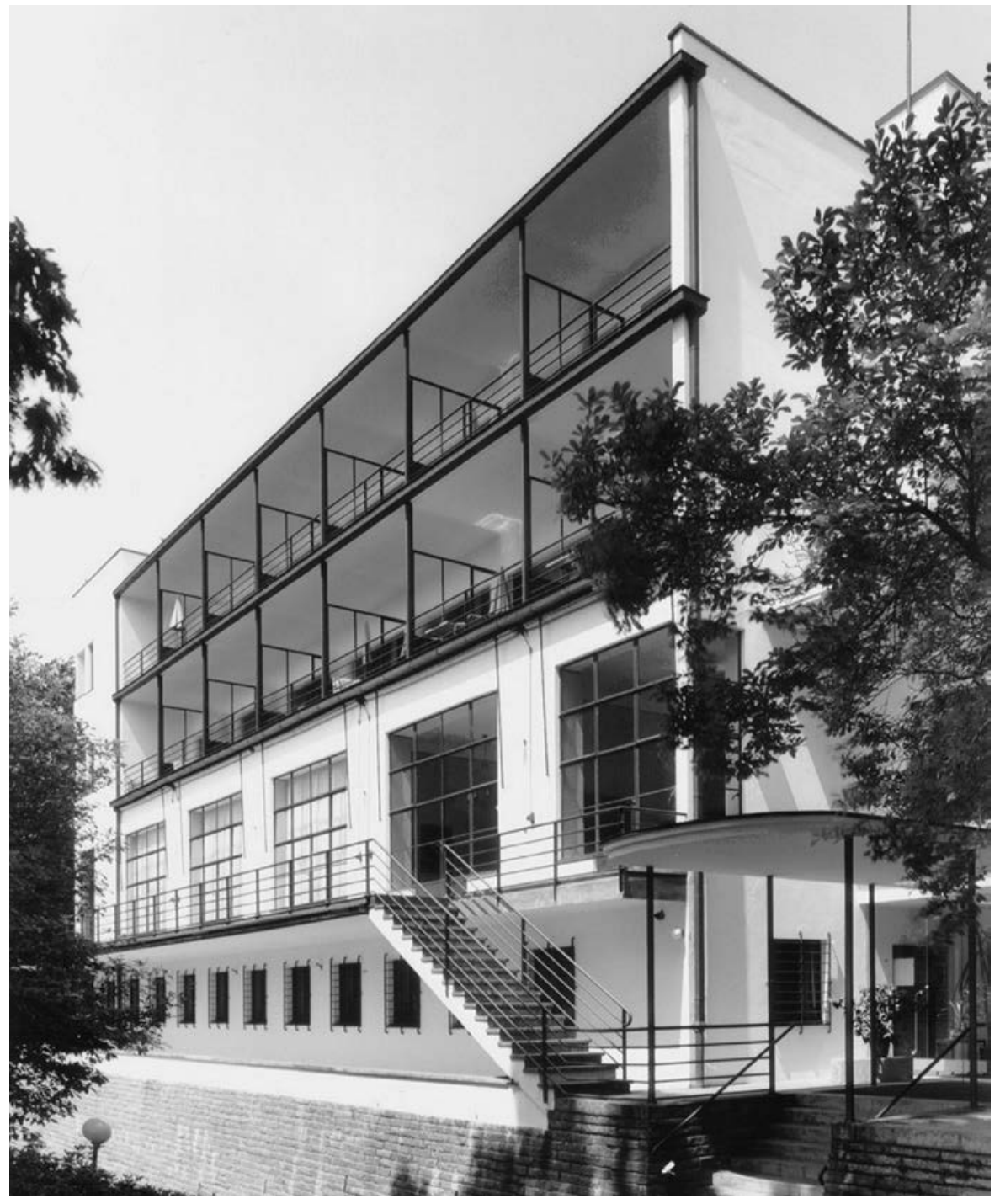

Figura 10: Hotel Monte Veritá en Ascona, 1927 (d'Anna, 1990) 
En cualquier caso, hay que reconocer que el origen común que comparten los hoteles con los sanatorios favoreció estos intercambios arquitectónicos. Sin embargo, la relevancia de la arquitectura sanatorial no se detuvo aquí. De hecho, su apertura al aire libre y al sol, así como su estandarización y racionalidad constructiva, la convirtieron en paradigma de una nueva forma de habitar. Así lo reconoce la literatura especializada de la época, cuando autores como Hermann Gescheit (1929), Richard Döcker (1929) o Sigfried Giedion (1929) la referencian con la intención de trasladar las ideas de higiene, salud y apertura a otros programas, en especial a la vivienda.

La eclosión de las revistas especializadas ${ }^{3}$ o los Congresos Internacionales de Arquitectura Moderna desempeñan un papel importante en la difusión de estas ideas. Sobre todo entre los miembros de una joven generación de arquitectos franceses que aborda la arquitectura para el ocio desde esa misma perspectiva renovada. Además, las terrazas y las cubiertas planas o los amplios ventanales, son particularmente adecuados para un estilo de vida ocioso al sol y al aire fresco. Un hedonismo importado por la élite social norteamericana a partir de 1925, cuando comenzó a broncearse bajo el sol estival del Mediterráneo francés y que pronto imitaría la alta sociedad europea.

Al inicio del siglo XIX este fragmento de litoral ya hacía parte del circuito anual mundano de esta clase social. De hecho, fue entonces cuando la gran temporada estival en torno a las estaciones turísticas termales y balnearias de moda se completó con una sesión invernal en la cálida región francesa. De modo que en su ida o en su regreso al sur, siguiendo la ruta que desde la época romántica asciende por las estaciones turísticas de los Alpes, se favoreció un intercambio cultural entre el mar y la montaña que se mantuvo en el siglo XX y que se manifestó en su arquitectura.

Esta translación al frente del mar de la arquitectura terapéutica alpina es evidente en el Hotel Relais Automobile en Juan-les-Pins, una propuesta de Gabriel Guevrekian para el Touring Club de France en 1923. Lo mismo sucede con la propuesta de André Lurçat para el Plage Hotel de 1927, con una planta articulada en forma de L y una extensa fachada meridional de sesenta habitaciones con terrazas en voladizo. Un esquema que Lurçat reproduce de nuevo en el Sanatorio de Durtol en Puy-de-Dôme y que se lleva al límite en el Hotel Nord-Sud en Calvi (Figura 11). Sobre todo en sus habitaciones, ajustadas al mínimo elemental de espacio, aire y luz que es necesario para vivir.

Esta idea del espacio mínimo habitable o Existenzminimum, tal como lo define Walter Gropius en su ponencia de 1929, ${ }^{4}$ se repite de nuevo en el Hotel Latitud 43 de Georges-Henri Pingusson en Saint-Tropez (Figura 12). Las líneas puras de su plan, con un cuerpo longitudinal serpenteante y abierto al paisaje litoral, evocan a un sanatorio en el frente del mar. De manera similar, los hoteles sanatorios y de fin de semana para la Ciutat del répos i vacances, próxima a Barcelona, reinciden en esta misma idea en 1932, pero en el contexto de una propuesta de ciudad para el ocio y el descanso laboral en la que se recupera el sentido terapéutico original de su arquitectura (Figura 13).

La prevención de la tuberculosis entre las clases trabajadoras, así como la reducción de su jornada laboral y el derecho al fin de semana, empujó al desarrollo de este tipo de intervenciones públicas a gran escala. De manera que aquellas ideas de higiene, de salud y de apertura al aire libre y al sol, privilegio de la arquitectura de las clases acomodadas, comenzaron 
a ser una necesidad ineludible para las masas en 1930. Unos postulados que tienen su origen en los tratamientos médicos antituberculosos de mediados del siglo XIX y que fueron los responsables de impulsar estas características arquitectónicas, tal como se ha demostrado a lo largo de este artículo.

Además, estas ciudades de vacaciones, a través de su planificación del tiempo libre, fomentan de una manera incipiente el turismo de masas en el frente litoral. Por lo tanto, aquella arquitectura tan representativa de la lucha contra la tuberculosis, comenzó a ser indisociable de la arquitectura para el turismo masivo de sol y playa. Sus estándares dimensionales y replicabilidad, su racionalidad constructiva y economía de medios, así como su programa funcional y la idoneidad de su arquitectura para un tiempo de ocio en las proximidades del mar, marcan desde entonces su identidad y explican la persistencia del modelo sanatorial. Sobre todo tras la Segunda Guerra Mundial, cuando converge con las necesidades que demanda la industria turística emergente (Figura 14).
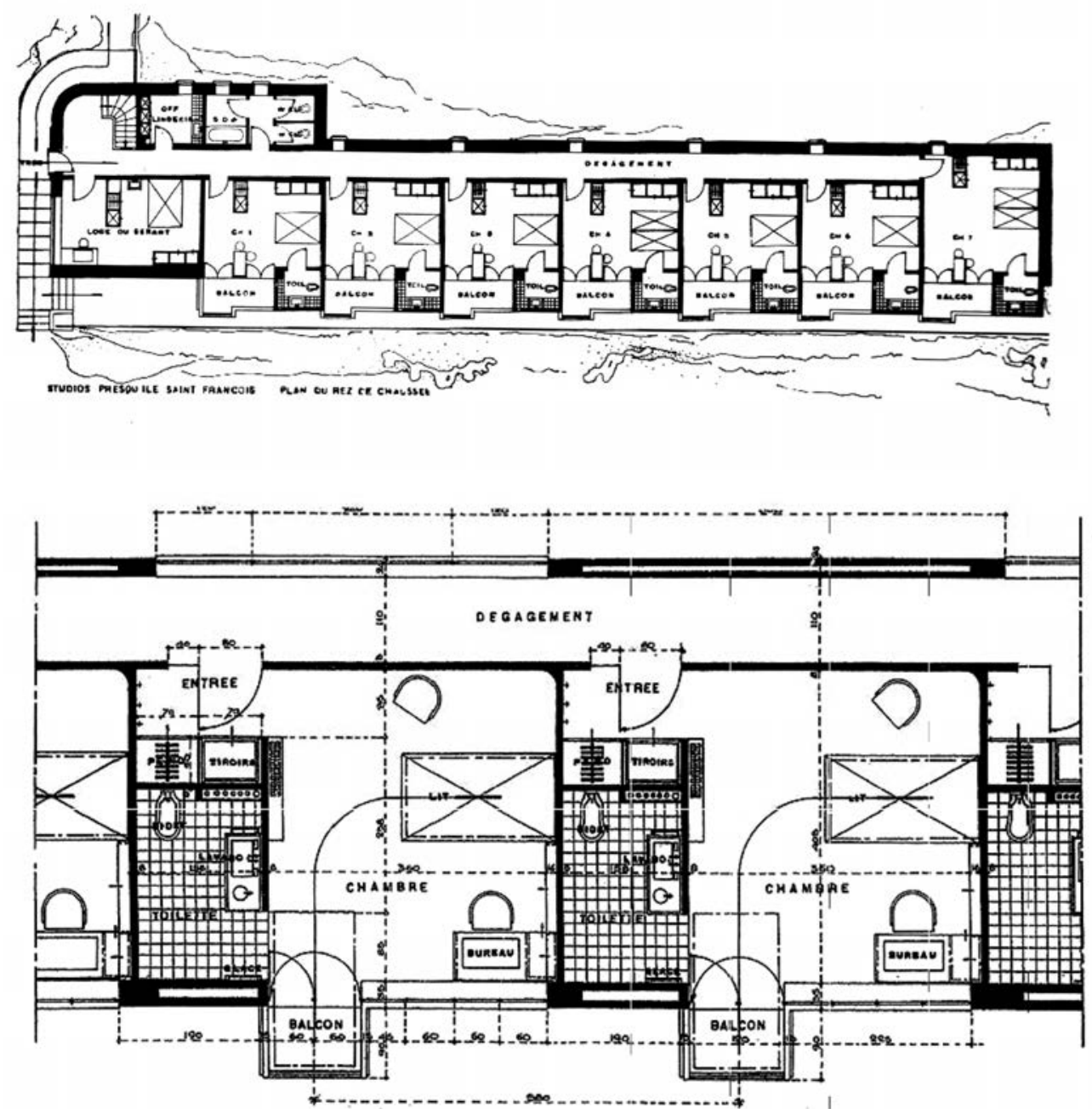

Figura 11: Planta del Hotel Nord-Sud y unidad de habitación del Durtol Sanatorium, 1929 (Vue..., s.f.) 


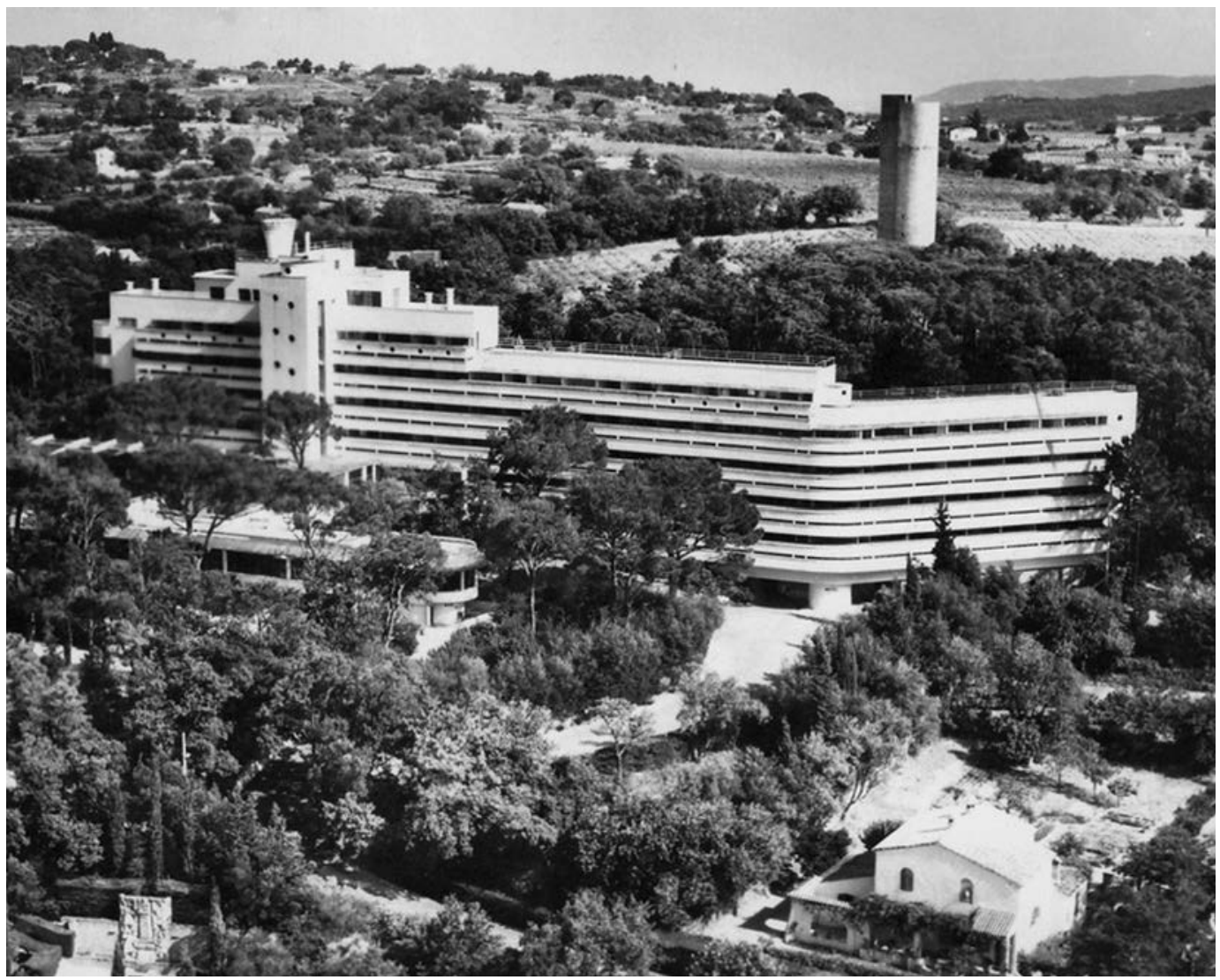

Figura 12: Hotel Latitud 43 en Saint-Tropez, 1929 (Pingusson, s.f.)

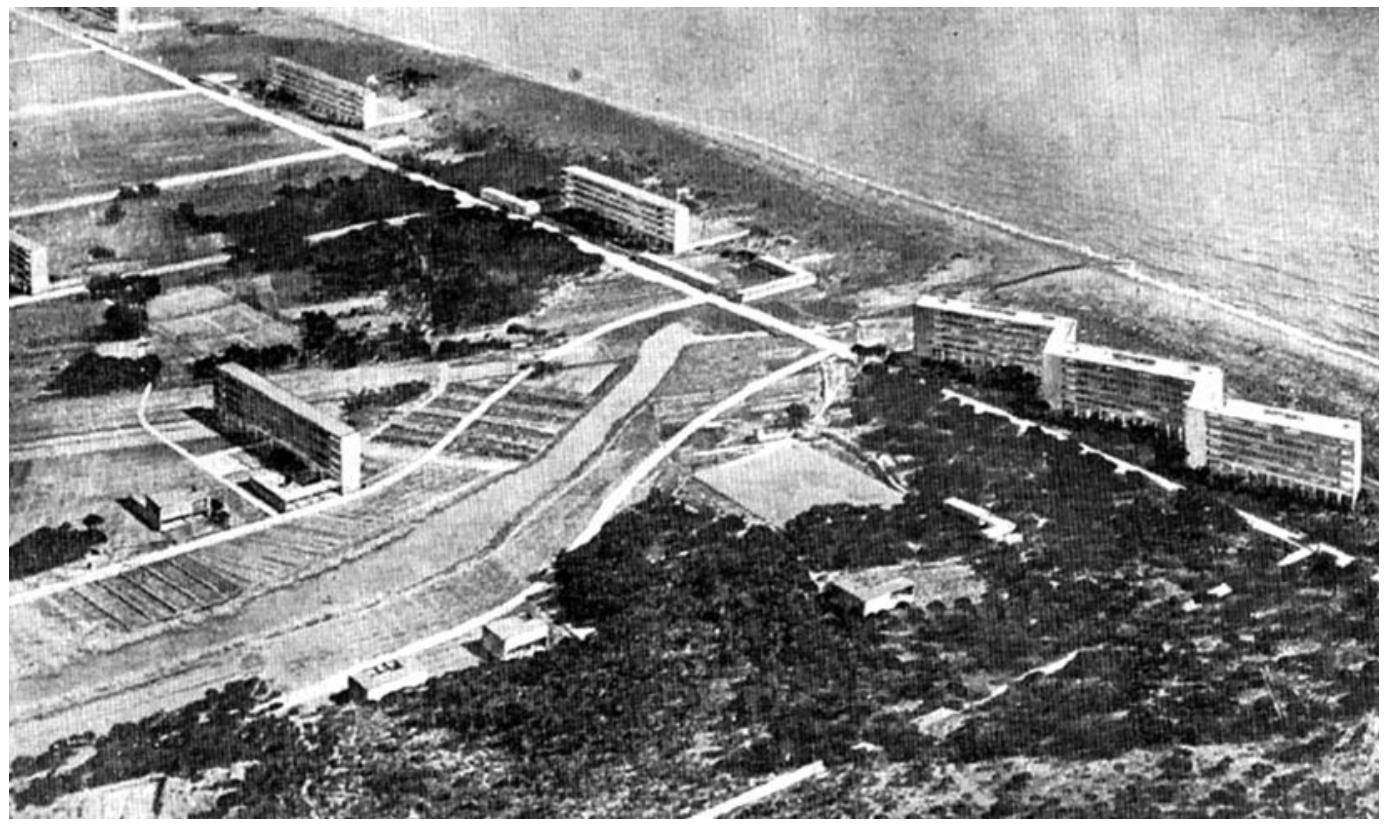

Figura 13: La Ciudad del Reposo y Vacaciones en Castelldefels, 1932 (Gatepac, 1932) 


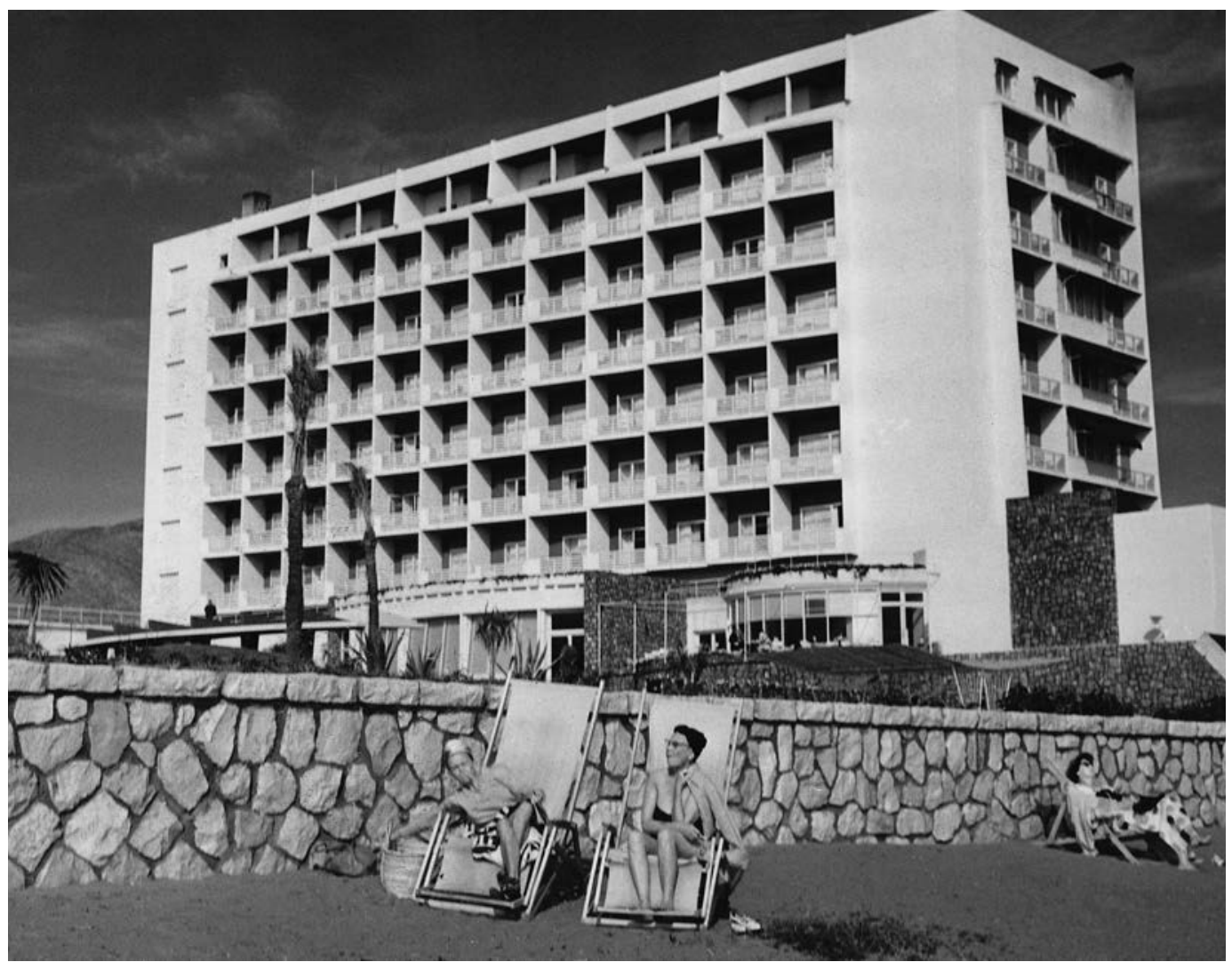

Figura 14: Hotel Pez Espada en Torremolinos, 1959 (Fernández-Fuster, 1961)

\section{Consideraciones finales}

La arquitectura para el turismo de masas es producto de la evolución arquitectónica que experimenta el hotel bajo la influencia de las terapias diseñadas para combatir la tuberculosis. Un progreso que se inicia en el contexto de la estación turística alpina de mediados del siglo XIX, cuando el viaje a las montañas adquiere un sentido sanitario para el tratamiento de la enfermedad y donde el hotel se convierte en el receptor inicial de la clientela tuberculosa. La virulencia de la enfermedad incentiva esta readecuación funcional ante la ausencia de unas instalaciones adecuadas a los requerimientos médicos, lo que sitúa al hotel de la estación turística en el origen evolutivo del sanatorio antituberculoso.

La aplicación de las terapias antituberculosas impulsa a continuación en la arquitectura del hotel un proceso de racionalización funcional y constructiva. Primero, rompe el sistema claustral para abrir los espacios al aire libre y al sol. Después, incentiva la integración de dispositivos arquitectónicos hasta entonces desconocidos: solárium, terrazas, amplios ventanales o cubiertas planas que extienden los beneficios del clima a todos los huéspedes. Además, las necesidades médicas promueven la sectorización del programa hotelero y la simplificación de su arquitectura, en particular, la distribución lineal de sus habitaciones para asegurar así el asoleo y la adecuada ventilación. 
El resultado es un hotel no muy diferente a un sanatorio. Unas semejanzas que se hace aún más evidente en el período entreguerras no solo en los hoteles de los Alpes, sino también en aquellos que aparecen en el litoral meridional francés. Concretamente en la Costa Azul, donde la arquitectura sanitaria resulta particularmente idónea para el estilo de vida hedonista que promueven las élites sociales internacionales. Sin embargo, su consolidación tipológica se produce a partir de 1930, cuando esa arquitectura que había sido tan representativa de la lucha contra la tuberculosis, comienza a ser intrínseca no solo al hotel sino también a la arquitectura para el turismo de masas.

Su vínculo se acrecienta con el final de la Segunda Guerra Mundial, cuando converge su arquitectura funcional con las necesidades que reclama la industria turística emergente. Desde entonces, la arquitectura para el turismo de masas se abrió de manera definitiva al paisaje para complacer el deseo del viajero de aproximarse al aire libre y al sol a través de sus terrazas. Un anhelo que tiene su origen en las terapias médicas antituberculosas de mediados del siglo XIX y que fueron las responsables de dar forma a su arquitectura. La misma que, aún hoy, continúa siendo parte esencial del imaginario colectivo asociado al turismo masivo de sol y de playa.

\section{NOTAS}

${ }^{1}$ Desde 1715 y hasta mediados del siglo XIX el estilo arquitectónico dominante fue el neoclasicismo, movimiento crítico del barroco y que revisitó las formas de la arquitectura del mundo clásico en Europa.

${ }^{2}$ A lo largo del siglo XIX, la arquitectura suiza adquirió una nostalgia romántica por aquella construcción vernácula en madera que representaba el chalet alpino, eje del revival del estilo arquitectónico romántico al que se hace referencia.

${ }^{3}$ L'Architecture Française, L'Architecte, Béton Armé, L'Architecture d'Aujord'hui o La Construction Moderne, catalogaban a través de bloques temáticos las obras más destacadas de Europa. También las publicaciones especializadas, como Hôspitaux et Sanatoria de Rouger Poulain (1930) y Hotels [et] Sanatoria de Gabriel Guevrekian (1930), ofrecían nuevas referencias arquitectónicas.

${ }^{4}$ Bajo el título de "Die Soziologischen Grundlagen der Minimalwohnung", el arquitecto Walter Gropius expone el concepto de vivienda mínima durante segundo Congreso Internacional de Arquitectura Moderna de 1929.

\section{REFERENCIAS}

AUSBAU...

Ausbau der Thurgauisch-Schaffhausischen Heilstätte in Davos. Schweizerische Bauzeitung, v.30, n.76, p.446-448. 1958.

CAMPBELL, Margaret.

What tuberculosis did for modernism: the influence of a curative environment on modernist design and architecture. Medical History, v.49, n.4, p.463-488. 2005.

CREMNITZER, Jean-Bernard.

Architecture et santé: les temps du sanatorium en France et en Europe. Paris: Picard. 2005.
D'ANNA, Marco.

Hotel Monte Verità, ristorante e auditórium. Disponible en: http://studiovacchini.ch/ opere/56. Acceso en: 10 sep. 2013. 1990.

DÖCKER, Richard.

Terrassentyp: Krankenhaus, Erholungsheim, Hotel, Bürohaus, Einfamilienhaus,

Sieglungshaus, Miethaus, und die Stadt. Sttutgart: Wedekind. 1929.

DUMAREST, Frédéric; TOBÉ, Frédéric; LEFEVRE, Pierre.

Le role du sanatorium modern. Bulletins et Mémoires de la Société Médicale de Passy, v.5, p.2844. nov. 1936. 
EAGER, J.M.

International tuberculosis conference at Berlin October 22 to October 26, 1902. Public Health Reports, v.17, n.51, p.2865-2873. 1902.

FERNÁNDEZ-FUSTER, Luis. Archivo fotográfico de la Dirección General de Turismo (1951-1992). Servicio Oficial de Fotografía, Registro $n^{\circ}$ 00383, Signatura caja 4 (Fondos de la Facultad de Empresa y Gestión Pública, Univiversidad de Zaragoza). 1961.

FUCHS, Caspar Friedrich.

Medizinische Geographie. Berlin: Alexander Duncker. 1853.

GATEPAC.

La ciudad de reposo que necesita Barcelona. Documentos de Arquitectura Contemporánea, v.7, p.24-31. 1932.

GESCHEIT, Hermann.

Neuzeitliche Hotels und Krankenhäuser; ausgeführte Bauten und Entwürfe. Berlin-Charlottenburg: Ernst Pollak Verlag. 1929.

GIEDION, Sigfried.

Befreites Wohnen: Licht, Luft, Öffnung. Zürich: Orell Füssli. 1929.

GUBLER, Fritz.

Great, grand and famous hotels. Crows Nest, NSW: Great, Grand \& Famous Pty Ltd. 2008.

GUEVREKIAN, Gabriel.

Hôtels [et] sanatoria. Paris: S. De Bonadona. 1930.

KNOPF, Sigard Adolphus.

Hermann Brehmer, and the semi-centennial celebration of Brehmer's sanatorium. New York: A. R. Elliot. 1904.

LÜTHI, Dave.

Eugène Jost: architecte du passé retrouvé.

Collection Archives de la construction moderne. Lausanne: Presses polytechniques et universitaires romandes. 2001.
OVERY, Paul.

Light, air and openness: modern architecture between the wars. London: Thames \& Hudson. 2008.

PINGUSSON, Georges Henri.

Vue aérienne. Fonds Pingusson. (Cité de l'architecture et du patrimoine. Institut français d'architecture, Paris). s.f.

POULAIN, Roger.

Hôspitaux et sanatoria. Paris: V. Freal. 1930.

RÜDIGER, Minna.

Luftliegekur in Falkenstein. Disponible en:

http://blauerheinrich.jimdo.com. Acceso en: 13 dic. 2013. 1894.

RUFENACHT, Frederick.

Sanatoria for consumptives: a critical and detailed description, together with an exposition of the open-air or hygienic treatment of phthisis. London: Swan Sonnenschein \& Co. 1899.

TOULIER, Bernard; CREMNITZER, Jean-Bernard. Histoire et réhabilitation des sanatoriums en Europe. Paris: Docomomo International. 2008.

TURBAN, Karl.

Tuberkulose-Arbeiten 1890-1909 aus Dr. Turbans Sanatorium Davos: bei Anlass des zwanzigjährigen Bestehens der Anstalt. Davos: Buchdruckerei. 1909.

VUE...

Vue des plans. Tirage NB contrecollé sur carton. Fonds André Lurçat. (Cité de l'architecture et du patrimoine. Institut français d'architecture, Paris). s.f.

WEHRLI, Gebrüder.

Rigi-Kulm, Grand-Hotel Schreiber,

Aussenansicht. Disponible en: http://www. helveticarchives.ch. Acceso en: 24 oct. 2013. 1897.

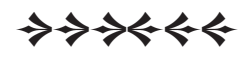

